\title{
ANÁLISES DA PRECIPITAÇÃO PLUVIAL DA BACIA DO SÃO JOSÉ DOS DOURADOS - SP
}

\author{
Alexandre Catania Greco de Oliveira ${ }^{(\mathrm{a})}$, Ana Claudia $\operatorname{Carfan}^{(\mathrm{b})}$, Jonas Teixeira Nery ${ }^{(\mathrm{c})}$ \\ (a) Colaborador Unesp, Unesp ICT São José dos Campos, alexandre.catania@gmail.com \\ (b) Docente Unesp, Unesp Ourinhos, acarfan@ terra.com.br \\ ${ }^{(c)}$ Prof. Dr. Unesp, Unesp Ourinhos, jonas@ ourinhos.unesp.br
}

\section{Eixo: CLIMATOLOGIA EM DIFERENTES NÍVEIS ESCALARES: MUDANÇAS E VARIABILIDADES}

\begin{abstract}
Resumo
O objetivo desse trabalho foi caracterizar a precipitação pluvial da bacia do rio São José dos Dourados, no Estado de São Paulo, a UGRHI - 18 com base nos dados obtidos junto a Agência Nacional de Águas (ANA). Foram utilizados parâmetros estatísticos, de regressão, coestimativas e corregionalização para analisar as diferenças sazonais de precipitação pluvial. Com os resultados obtidos pode-se concluir que as chuvas na bacia do rio São José dos Dourados sofrem variabilidade temporal, espacial e essa variabilidade também pode estar associada a ocorrência de eventos El Niño.
\end{abstract}

Palavras chave: variabilidade, anomalias, precipitação, ENOS, UGRHI.

\section{Introdução:}

Por localizar-se na divisa das regiões do centro-oeste e do sudeste brasileiro, entre os estados de São Paulo e Mato Grosso do Sul a bacia hidrográfica do rio São José dos Dourados (BHSJD), ou seja, a Unidade de Gerenciamento de Recursos Hídricos 18 do Estado de São Paulo situa-se próxima ao tópico de capricórnio e suas características climáticas sofrem influências dos sistemas atmosféricos de origem tropical e extratropical, (CAVALCANTI, 2009). No centro-norte da bacia sedimentar do Paraná, de predomínio da formação Serra Geral, Grupos Bauru/Caiuá, localizada entre o rio Grande ao norte e o rio Tietê ao sul, com a foz do rio São José dos Dourados no reservatório da Usina Hidrelétrica de Ilha Solteira, essa bacia recebe influência de diversos fenômenos atmosféricos e também possuí elementos e fatores climáticos que caracterizam a região.

Na dinâmica da circulação da atmosfera, encontra-se vasto material que ajuda a esclarecer sobre as variações regionais e temporais de grande escala no clima da região, por exemplo, a Alta da Bolívia, predominantemente a noroeste desta região, comporta-se como um sistema típico e estacionário nos altos níveis, devido ao forte aquecimento convectivo (liberação de calor latente) da atmosfera na Amazônia durante o verão, resultando nos baixos níveis em uma região de baixa pressão chamada Baixa do Chaco, (VIRJI, 1981 et al.) que atuam para gerar convergência e movimentos ascendentes necessários a convecção. 
A circulação anticiclônica associada a Alta da Bolívia desloca-se para o norte em junho e julho chegando a atingir áreas na Venezuela e na Colômbia e pode influenciar o clima desta região à condições adversas, tais como secas, enchentes e condições de tempo severas associadas a Complexos Convectivos de Mesoescala (CCMs), (PAEGLE, 1998 et al.).

A variação sazonal do regime de precipitação na região da bacia hidrográfica de São José dos Dourados possui duas estações bem definidas, no inverno uma estação seca e no verão uma chuvosa, porém a contribuição dos CCMs influenciados pelo forte escoamento em baixos níveis da atmosfera a leste dos Andes atua no transporte de massa de ar tropical distribuindo chuva também no inverno pela região, (CAVALCANTI, 2009).

O noroeste do Estado de São Paulo apresenta médias de temperaturas superiores a $21^{\circ} \mathrm{C}$, pois possuí baixas altimetrias e relativa distância do oceano, localizado na faixa de transição para os domínios doCerrado, que propiciam o surgimento desse padrão de altas temperaturas, preponderando a influência do fator continentalidade para o caso.

No Planalto Ocidental Paulista destacam-se as planícies das grandes bacias hidrográficas, onde as frentes polares atuam como fator gerador das chuvas na região, fator relevante em sua previsibilidade influenciando na alta variabilidade devido as incursões das massas polares induzindo a maiores totais pluviométricos, no período em que essas frentes se tornam mais frequentes, (CAVALCANTI, 2009).

Entre as menores do Estado de São Paulo, a UGRHI - 18 (Unidade de Gerenciamento de Recursos Hídricos) possui sub-bacias em sua maioria de pequeno porte que deságuam no reservatório formado no rio Paraná pela barragem da UHE (Usina Hidrelétrica) Ilha Solteira, destacando o rio São José dos Dourados, seu reservatório atinge a confluência dos rios Grande e Paranaíba a montante, formadores do rio Paraná e possuí no reservatório uma interligação com a UHE de Três Irmãos no rio Tietê (UGRHI - 19), via canal Pereira Barreto.

Na região da UGRHI - 18, encontram-se os Aquíferos Guarani, Bauru e Serra Geral e produziram $0,464 \mathrm{~m} / \mathrm{s}$ distribuídos em 136 poços conforme demanda requerida, observou-se desde 1994concentrações de cromo elevadas no Sistema Aquífero Bauru, onde as UGRHI’s 18 e 21 apresentaram as maiores concentrações, exigindo uma maior fiscalização na extração de águas subterrâneas para ajudar no diagnóstico/prognóstico desses problemas.

Uma vazão média de $16 \mathrm{~m}$ 33/s (Q95\%) mostra a necessidade de verificação, já que esta bacia hidrográfica abastece 225.218 habitantes da região caso haja a contaminação das águas superficiais dessa bacia de drenagem. São $6.783 \mathrm{~km}^{2}$ de área de drenagem, onde se destacam os córregos Cabeceira Comprida, Córrego da Água Limpa, Ribeirão da Ponte Pensa, Ribeirão Coqueiro e o Rio 


\section{OS DESAFIOS DA GEOGRAFIA FÍSICA NA FRONTEIRA DO CONHECIMENTO \\ Instituto de Geociências - Unicamp \\ Campinas - SP \\ 28 de Junho à 02 de Julho de 2017}

São José dos Dourados. A área não possui unidades de conservação e apenas 6,5\% do território é ocupado por vegetação natural remanescente.

Possui clima megatérmico, típico de savanas, o noroeste do Estado de São Paulo, mais quente, pertence ao tipo Aw da classificação de Koppen, ou seja, tropical chuvoso com inverno seco e mês mais frio com temperatura média superior a $18{ }^{\circ} \mathrm{C}$. O mês mais seco tem precipitação inferior a 60 mmcom período chuvoso que se atrasa para o outono, (CEPAGRI - UNICAMP).

A área core do domínio morfoclimático do cerrado, característica do centro-oeste brasileiro e de paisagem transicional, também se expressam na BHSJD, (MENDONÇA, 2007). Devido sua posição geográfica, atuam nesta região os sistemas atmosféricos equatoriais Continental e Marítimo (cE e mE), as Massas de Ar Tropicais (cT e mT), além de notável atuação do sistema extratropical, como as Massas Polares Marítimas (mP) frentes frias, implicando multiplicidade de tipos de tempo durante o ano e a tropicalidade úmida-seca garante expressiva sazonalidade, com exuberante ritmo anual definidos por duas estações, sendo que os tempos quentes e úmidos concentram-se no verão e quentes e secos no inverno, onde pontualmente ocorrem quedas de temperaturas.

Os três meses menos chuvosos do ano nesse subtipo climático são junho, julho e agosto, (MENDONÇA, 2007), onde se reduz claramente as temperaturas de forma expressiva durante a noite, porém essa oscilação térmica não aparece nos totais médios mensais, pois o dia continua bem quente no inverno.

Como o setor primário predomina na economia regional da UGRHI - 18, os famosos boias-frias são os que enfrentam essas altas temperaturas diurnas, onde a agroindústria de cana de açúcar e laranja bem como a produção de carne bovina recebem destaque para a produção regional, a longevidade e baixa renda são também outras das grandes características dos municípios de poucos habitantes da região. Vale destacar que cerca de $20 \%$ desses municípios estão entre os piores no Índice Paulista de Responsabilidade Social, índice semelhante ao IDH (Índice de Desenvolvimento Humano) das Nações Unidas que objetiva facilitar a identificação das necessidades de políticas públicas nos municípios paulistas, ou seja, mais uma ferramenta para planejamento, que busca traçar propostas fundamentadas em "diagnósticos abrangentes" (ALESP, 2016), evidenciando a vulnerabilidade as mudanças climáticas desta região.

Para o presente trabalho analisou-se o fenômeno El Niño-Oscilação Sul (ENOS) que é caracterizado por fortes anomalias de temperatura da superfície do mar do Oceano Pacífico Equatorial e sua relação com a bacia hidrográfica de São José dos Dourados. 
Devido a dinâmica atmosférica da América do Sul, principalmente a sazonalidade da radiação, a extensão longitudinal do continente e a diminuição de terras continentais conforme aumento da latitude, a atuação de massas de ar equatoriais, tropicais e polares e a interação desses fenômenos marcam predominantemente a região.

O predomínio de massas de ar de origem oceânica propicia ao continente a formação de ambientes climáticos com considerável umidade, porém essa dinâmica atmosférica associada ao relevo formam paisagens semiáridas e até mesmo desérticas sobre o continente sul americano.

A influência dos ENO's no clima do Brasil está comprovada há alguns anos, sua variabilidade regional (positiva ou negativa) também é significativa em períodos de ocorrência.

El Niño representa o aquecimento anormal das águas superficiais e sub-superficiais do oceano Pacífico Equatorial, onde se considera também o enfraquecimento dos ventos alísios (que "sopram" de leste para oeste) na região equatorial, mudando a circulação da atmosfera nos níveis baixos e altos, determinando os padrões de transporte de umidade, portanto variações na distribuição das chuvas em regiões tropicais e de latitudes médias e altas, (OLIVEIRA, 2001).

O ENOS ou El Niño Oscilação Sul representa de forma genérica um fenômeno de interação atmosfera-oceano, associado a alterações dos padrões normais da Temperatura da Superfície do Mar (TSM) e dos ventos alísios na região do Pacífico Equatorial, entre a Costa Peruana e o Pacifico oeste próximo à Austrália, (OLIVEIRA, 2001). O Índice de Oscilação Sul (IOS) representa a diferença entre a pressão ao nível do mar entre o Pacífico Central (Taiti) e o Pacífico do Oeste (Darwin/Austrália). Esse índice está relacionado com as mudanças na circulação atmosférica nos níveis baixos da atmosfera, consequência do aquecimento/resfriamento das águas superficiais na região. Valores negativos e positivos do IOS são indicadores da ocorrência do El Niño e La Niña respectivamente, (OLIVEIRA, 2001).

No presente trabalho considera-se a influência das principais massas de ar atuantes na América do Sul e suas características que propiciam a distribuição peculiar das chuvas sobre o continente, onde uma massa de ar pode ser caracterizada pela homogeneidade das suas propriedades termodinâmicas temperatura e umidade - e permanecem sobre a superfície terrestre por um período em estado de equilíbrio e a região de sua origem a caracteriza, ou seja, denomina que tipo de massa de ar ela é, (VIANELLO, 2012).

A Massa Equatorial Continental - mcE, que a partir da divergência dos alísios na região amazônica, região dominada por baixas pressões, cuja característica singular é a predominância de movimentos convectivos, pois a farta e caudalosa rede de drenagem da região coberta por uma exuberante e densa 
floresta também contribuem para sua intensificação, no verão austral atinge sua máxima em direção sul influenciando toda a atmosfera interiorana da América do Sul e retraindo no inverno.

A Massa Equatorial Marítima - mEm que ocorre sobre os oceanos Atlântico e Pacífico e resulta da convergência dos alísios deslocando até latitudes de $8^{\circ} \mathrm{S}$ no verão, (VIANELLO, 2012).

A Massa Tropical Continental - mcT predominante sobre a região do Chaco, dá origem a massa de ar quente e seca devido ao grande aquecimento da superfície no verão. A baixa pressão associada, instável, provoca precipitações fracas favorecendo o aquecimento durante o dia e o resfriamento a noite.

Durante a atuação das Massas Tropical Marítima - mTm na dinâmica atmosférica da América do Sul, que são formadas sobre os oceanos Pacífico e Atlântico Sul, esses anticiclones influenciam nos tipos climáticos de todo o território brasileiro, pois possuem características de temperatura e umidade específicas, onde duas camadas de ar sendo uma mais fria na superfície e outra mais quente superior, causam inversão, que por meio de correntes de leste são atraídas pelo continente, onde devido a orografia litorânea provoca pouca precipitação na região leste do continente, porém influencia todo o clima do Brasil quando se desloca para oeste sobre o continente ocasionando o tempo seco predominante no inverno.

A Massa Polar Marítima - mPm, ou seja, as frentes frias tem sua origem no sul, em $60^{\circ} \mathrm{S}$ de latitude aproximadamente, normalmente estáveis nessas regiões, porém quando atraída pelas baixas pressões tropicais e equatoriais atingem a calha natural de drenagem da bacia Platina no continente tornam-se instáveis e chegam a baixas latitudes provocando a friagem de todo centro, sul e leste da América do Sul. "Dos permanentes deslocamentos das mP's em direção norte e do choque entre suas características e as do ambiente climático tropical e equatorial originam-se os mecanismos frontogenéticos austrais" (MENDONÇA,2007). Essas massas não se misturam imediatamente quando ocorrem seus encontros, há variações bruscas nos campos de temperatura, dos ventos e outros elementos meteorológicos, onde essa zona de transição, que por analogia ao encontro de forças bélicas confrontando-se num campo de batalha é denominada zona frontal ou frente, (VIANELLO, 2012).

\section{Material e Procedimentos Metodológicos:}

Foi necessário fazer o "download" no site Hidroweb, gerenciado pela ANA (Agência Nacional de Águas), dos pontos em formato "shapefile" referentes a localização das estações pluviométricas do Brasil, onde no mesmo site consegue-se baixar também a hidrografia e os limites das bacias hidrográficas nacionais, conforme Figura 1. Elaborou-se o mapa de localização das estações pluviométricas, utilizando a ferramenta de seleção por localização do SIG (Sistema de Informação 


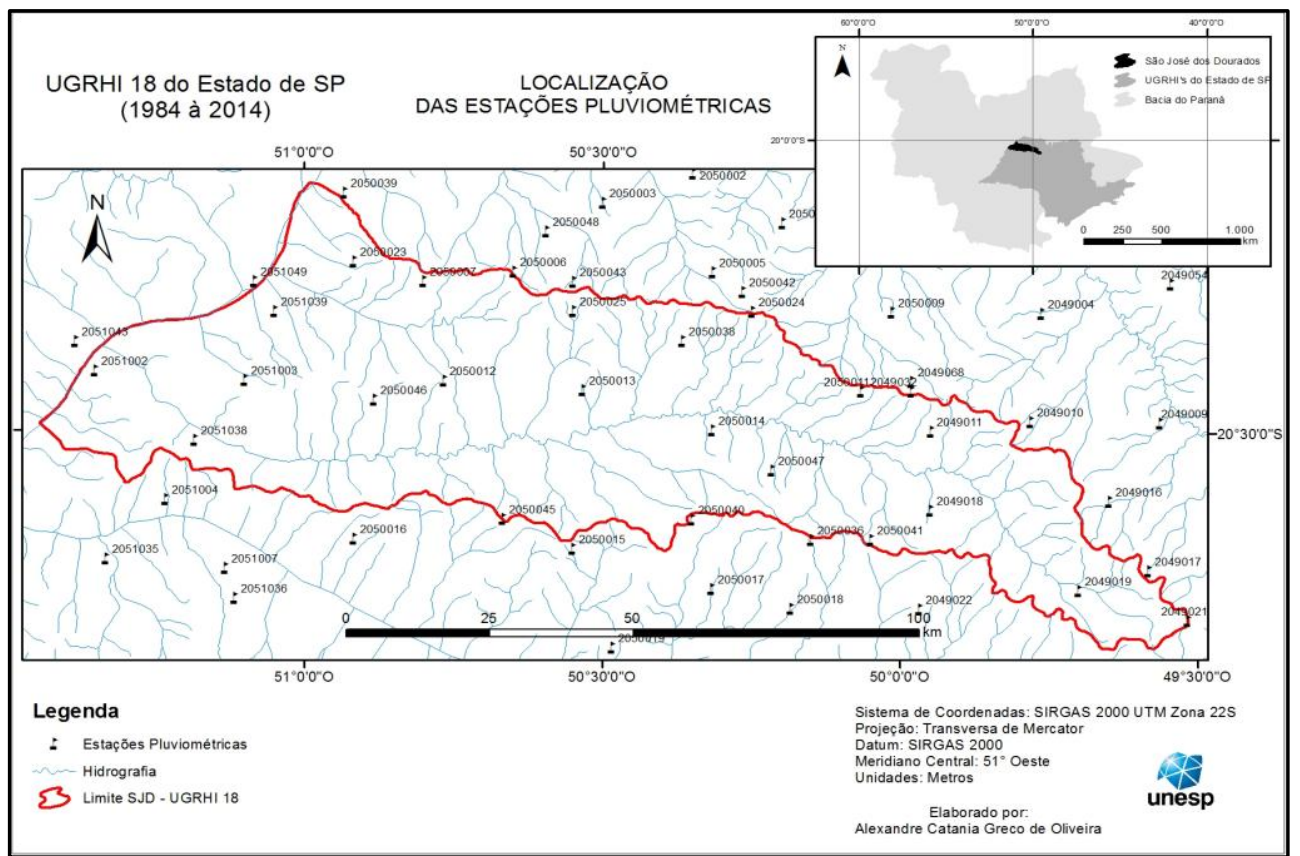

Figura 1:Localização da bacia hidrográfica analisada e estações do entorno.

Geográfica) Arcgis da fabricante Esri, a busca por estações próximas do limite da bacia hidrográfica de São José dos Dourados (BHSJD), a fim de limitar as estações para análise e adequar os dados a escala proposta no trabalho. Apesar da quantidade expressiva de estações pluviométricas mapeadas na Figura 1, nem todas possuem dados disponibilizados e após conferência e filtragem dos dados para o período analisado, verificou-se apenas as estações da Figura 2 continham dados que poderiam ser utilizados no presente trabalho.

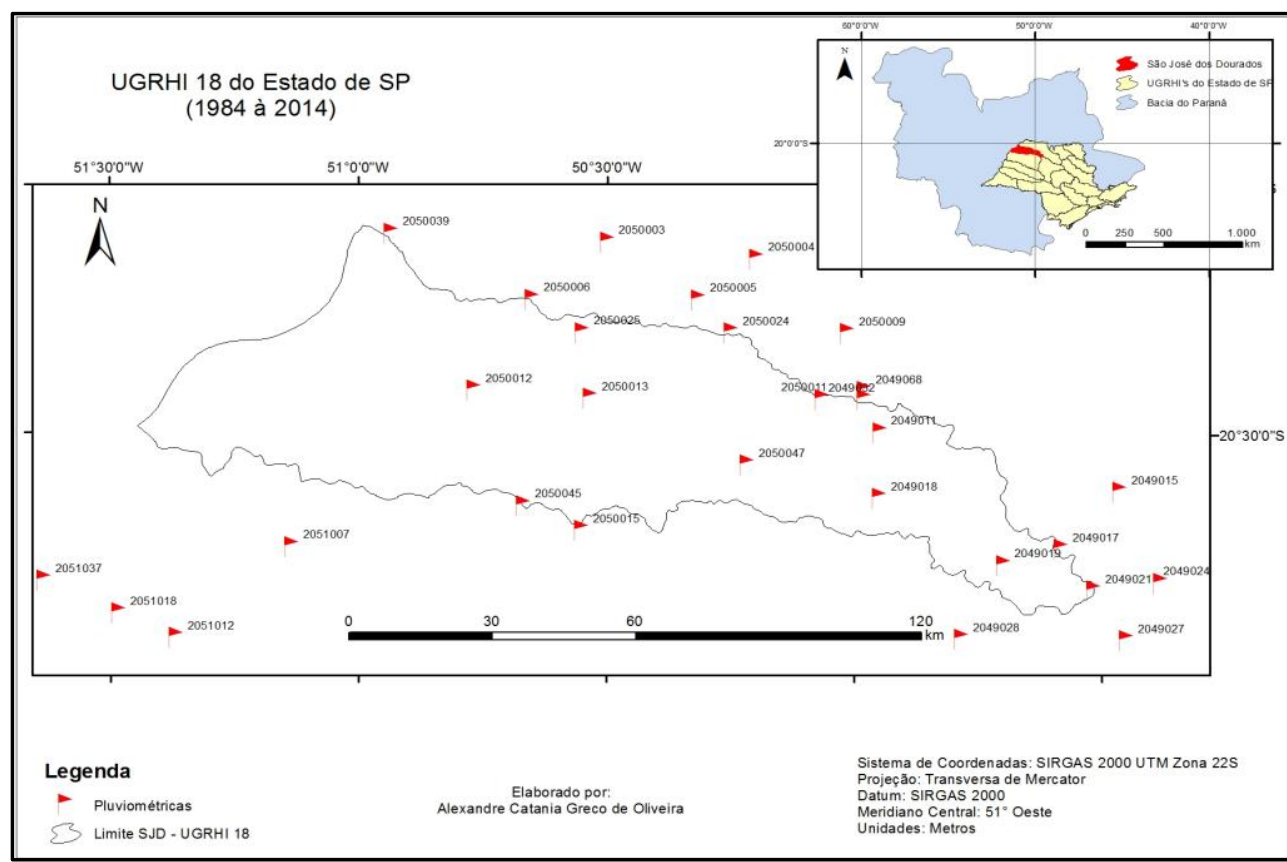

Figura 2: Bacia hidrográfica (UGRHI - 18) e estações com dados utilizados no período. 
Localizadas as estações do entorno da BHSJD houve necessidade de filtrar novamente as estações com os melhores dados, ou seja, as estações que possuem alto grau de preenchimento, acima de $90 \%$ dos dados, contribuindo para realização de análises mais próximas a realidade. Algumas estações divulgadas pela ANA apresentam muitas falhas no preenchimento inviabilizando o uso para trabalhos científicos. Este método consiste em fazer o download dos dados e avaliar o período mínimo de trinta anos para cada estação e este período deve ser idêntico as demais. Muitas estações foram instaladas recentemente e outras aparentemente deixaram de funcionar nos anos 2000, inviabilizando sua utilização.

A partir da filtragem dos dados e definição das estações a serem trabalhadas, conforme Figura 2, foi possível fazer o tratamento e correção dos problemas com esses dados disponibilizados pela ANA, trabalhando em planilhas ou tabelas matriciais.

Para o estudo de um fenômeno espacial, algumas variáveis podem estar subamostradas e outras superamostradas, porém se há uma correlação entre as variáveis utiliza-se um conjunto de ferramentas da Geoestatística para realizar coestimativas, (YAMAMOTO, 2013).

No presente trabalho foi utilizado o método da regressão linear simples para o preenchimento de falhas, estimando um valor esperado para uma variável dependente. $\mathrm{O}$ método de regressão linear consiste em utilizar regressões lineares simples ou múltipla para o preenchimento de falhas. $\mathrm{Na}$ regressão linear simples, as precipitações da estação com falhas de dados e de uma estação próxima são correlacionadas, (BERTONI \& TUCCI, 2001). É chamada linear porque considera que a relação da resposta às variáveis é uma função linear dos parâmetros lidos em sua correlata. A autocorrelação espacial ou corregionalização é uma medida geral de associação espacial existente no conjunto de dados, podendo variar de -1 e 1 e quanto mais próxima de 1 , mais alta a semelhança do atributo aos valores das estações próximas.

O Libre Office possui o programa "Calc" que faz a correlação de dados na opção da barra de ferramentas "dados", em seguida "estatísticas" e posteriormente "correlação" para obter a matriz de correlação das estações pluviométricas. Baseado no resultado da matriz, onde cada estação possui uma relação com alguma estação próxima, é necessário gerar um gráfico de regressão composto pela melhor correlação entre as estações, em seguida gera-se a fórmula da regressão para preenchimento da planilha subamostrada. Após preenchimento é possível gerar os mapas de padrões de pluviosidade para região, utilizando o método de krigagem disponível no SIG Arcgis, fabricado pela Esri, na toolbox "SpatialAnalisty Tools", "Interpolation", "Kriging”, onde se utilizou do método 


\section{OS DESAFIOS DA GEOGRAFIA FÍSICA NA FRONTEIRA DO CONHECIMENTO \\ Instituto de Geociências - Unicamp \\ Campinas - SP \\ 28 de Junho à 02 de Julho de 2017}

préprogramado para geração destes mapas, o método consiste em cokrigagem simples, de transformação do tipo pontuação normal, utilizando método de aproximação Kernel Gaussiana e Anisotrópica.

Os gráficos de regressão gerados foram agrupados em uma única figura para exemplificar como se estabeleceu a correlação entre as estações. A Figura 3 apresenta de forma sucinta parte do trabalho desenvolvido para preenchimento das lacunas de dados de algumas das estações pluviométricas da região. Foi necessário o estabelecimento de critérios de exclusão dos dados, estabeleceu-se como critério para utilização dos dados e da correlação entre estações, o limite de correlação superior ao de $70 \%$, todas as correlações abaixo deste valor seriam descartadas do processo. Para cada par de estações que gerasse um coeficiente de determinação $\left(r^{2}\right)$ abaixo de 0,70 , escolhia-se outra estação para preenchimento, garantindo a qualidade dos dados e uma correta análise posterior. Após o preenchimento de todas as lacunas foi possível gerar os mapas pluviométricos.

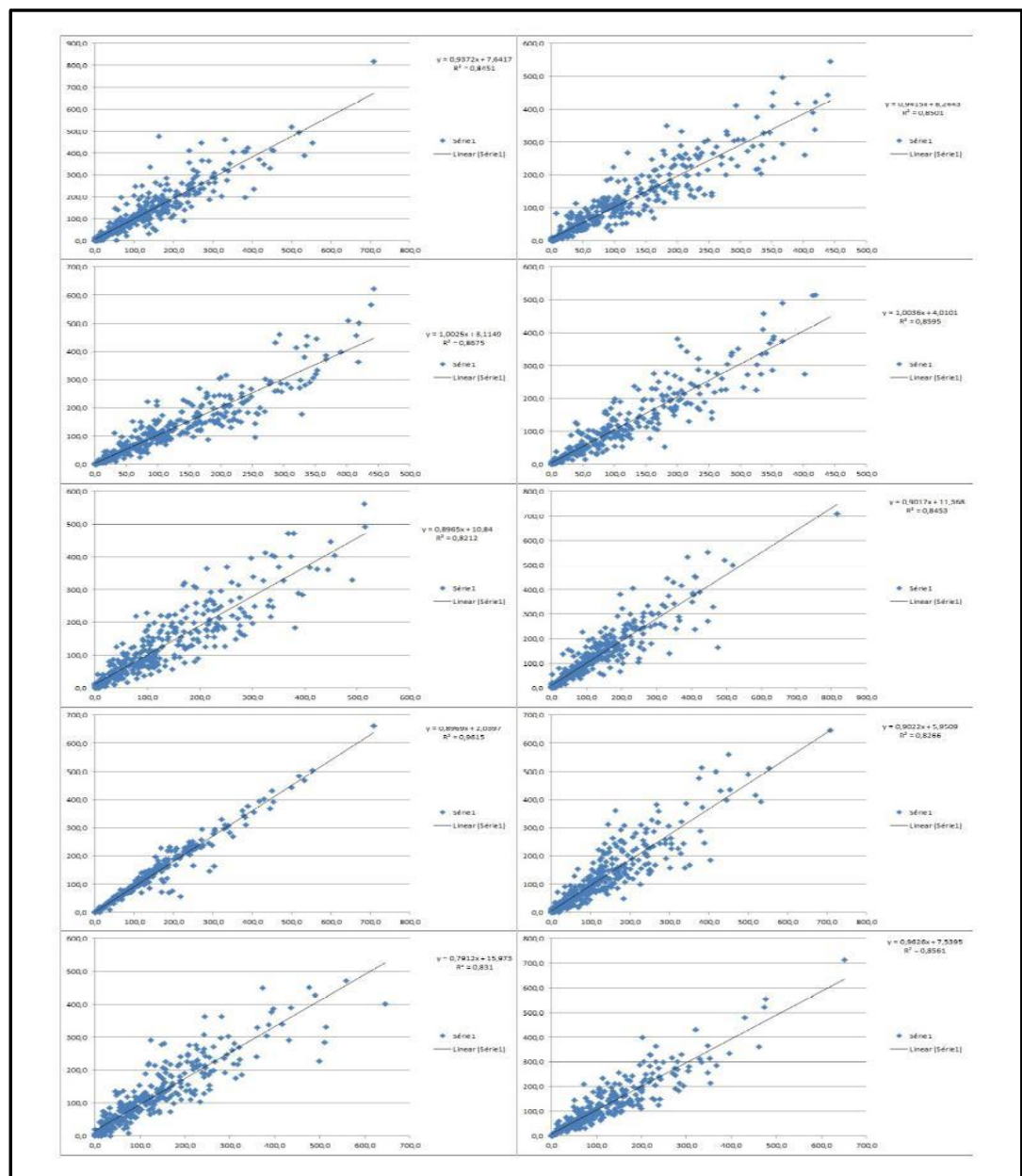

Figura 3: Exemplo de análise de regressão entre estações pluviométricas para preenchimento dos dados. 
Para a validação dos dados analisou-se os métodos empregados e a resposta sobre as estimativas regionalizadas, observou-se coerência nos mapas expostos onde nos dados para janeiros de 83 a 86 ocorreu pequena subestimação da ordem de 2,9\% e para os janeiros de 2005 a 2008 onde os dados

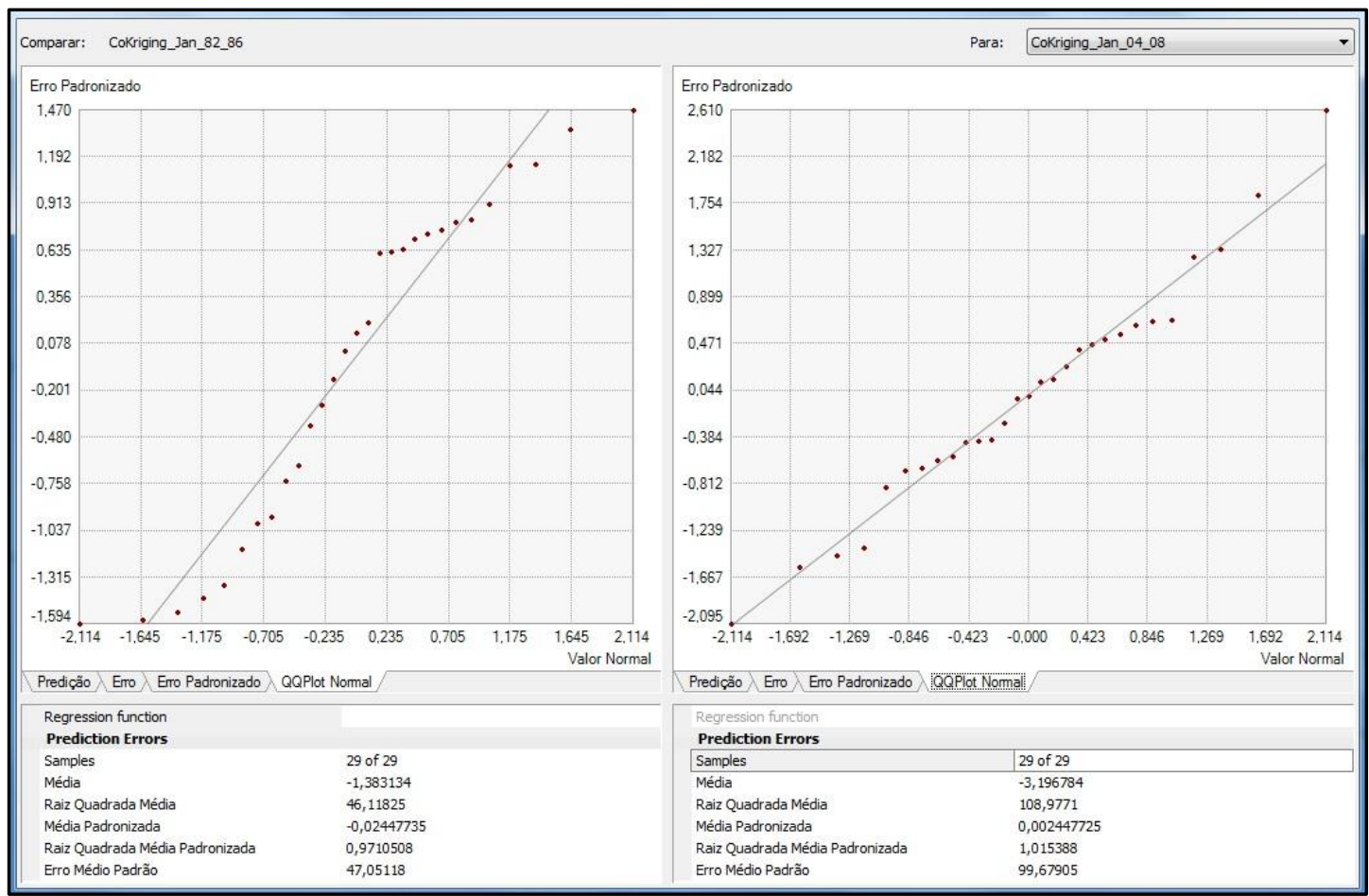

Figura 4:Validação e erro médio para os mapas apresentados.

estão superestimados em 1,5 \%, a Figura 4 resume a análise de validação dos dados apresentados.

\section{Análise dos Resultados:}

O encontro das principais massas de ar citadas anteriormente recebendo influência do El Niño, propiciam alterações no clima local da bacia hidrográfica de São José dos Dourados, onde o presente trabalho pretende analisar e relacionar o fenômeno ENOS ao volume pluviométrico da área estudada.

A baciahidrográfica é umaárea de captação natural da água de precipitaçãoquefazconvergir o escoamentopara um únicoponto de saída. A baciahidrográficacompõe-se de um conjunto de superfíciesvertentes e de umarede de drenagemformadaporcursos de águaqueconfluematéresultarem um leitoúnico no seuexutório, (TUCCI, 1997).

A baciahidrográficapodeserentãoconsiderada um entesistêmico, a questão da escala a serutilizadadepende do problema a sersolucionado.Diz-se que o tamanho ideal de baciahidrográfica é aquelequeincorporatoda a problemática de interesse.Esseconceitosistêmicoadapta-se muitobemaossistemas de gestão de recursoshídricos.Sobre o territóriodefinidocomobaciahidrográfica é 
que se desenvolvem as atividadeshumanas. Todas as áreasurbanas, industriais, agrícolasou de preservaçãofazem parte de algumabaciahidrográfica.Pode-se dizerque, no seuexutório, estarãorepresentadostodososprocessosquefazem parte do seusistema. O quealiocorre é consequência

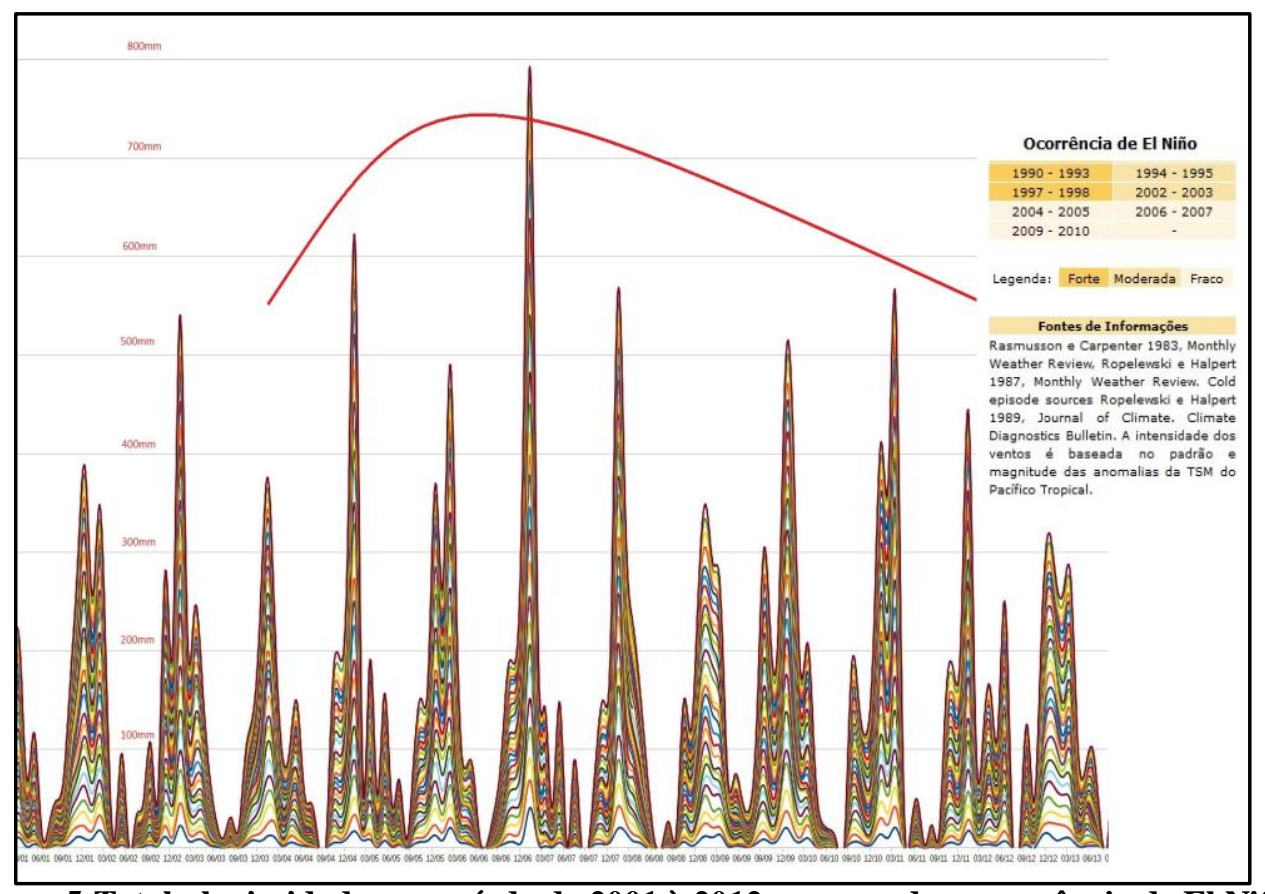

Figura 5:Total pluviosidade no período de 2001 à 2012 comparado a ocorrência de El Niño.

das formas de ocupação do território e da utilização das águasqueparaaliconvergem, (PORTO, 2008).

Para o período analisado de 31 anos, ou seja, 1984 à 2014, um padrão de influência é percebido para a região da bacia hidrográfica. A Figura 5 a seguir, mostra um período de 12 anos, onde destaca-se uma elevação no volume de chuvas nos verões de 2005, 2006, 2007 e 2008, ilustrado pela linha vermelha no centro da figura. Observam-se ciclos de baixa pluviosidade também no período analisado, fenômeno este que também é inversamente proporcional à ocorrência de ENOS, pois sua intensidade quando baixa aumenta o volume de chuvas da região. A Figura 6 abaixo apresenta os totais pluviométricos para um pequeno ciclo e a ocorrência de El Niño muito forte no início da década de 1980. 


\section{OS DESAFIOS DA GEOGRAFIA FÍSICA NA FRONTEIRA DO CONHECIMENTO Instituto de Geociências - Unicamp Campinas - SP 28 de Junho à 02 de Julho de 2017}

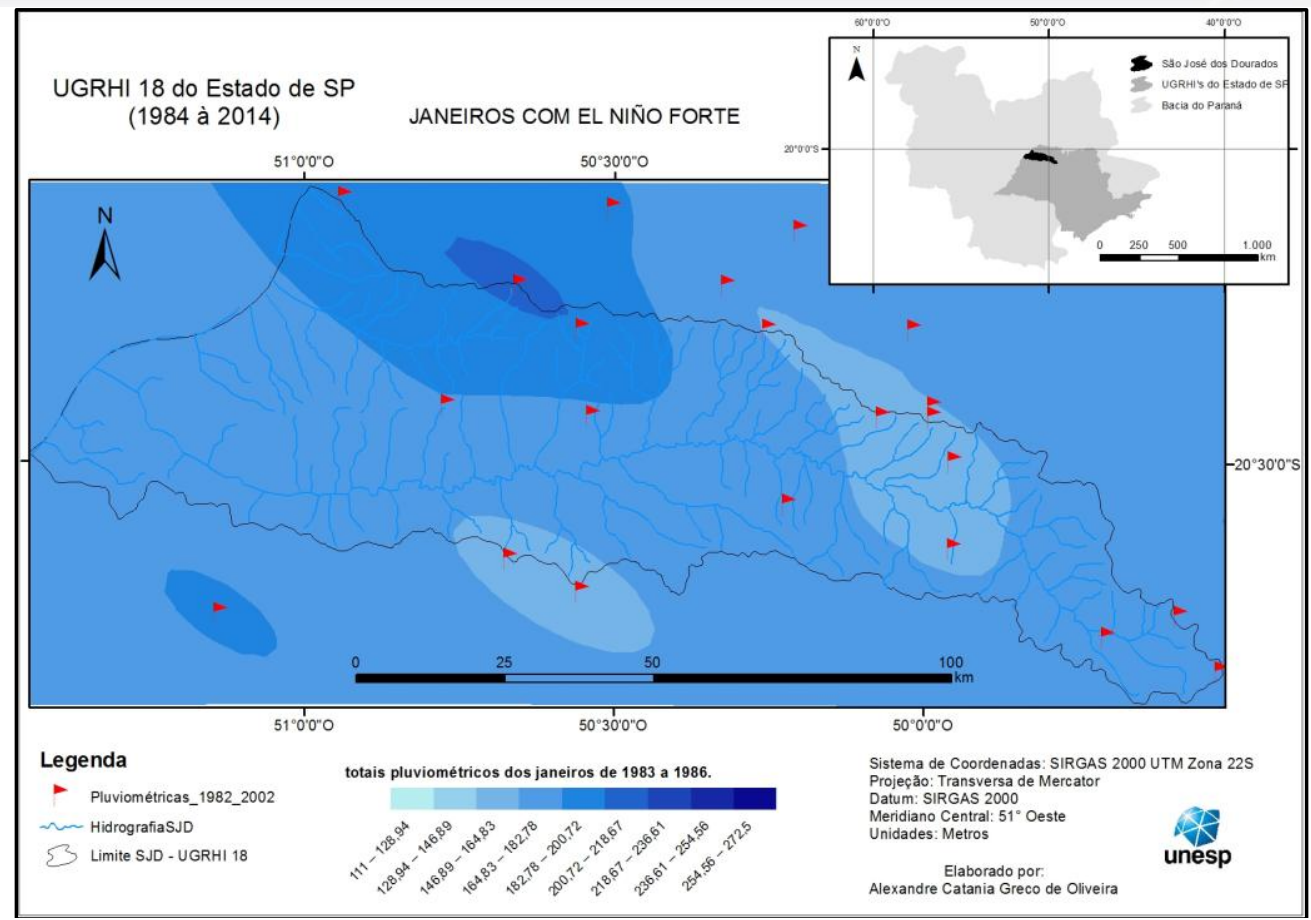

Figura 6: Janeiros entre os anos de 1983 a 1986, período considerado com El Niño forte.

Para os meses de janeiro entre 2005 a 2008, representado no mapa a seguir, na Figura 7 ocorre o inverso, ou seja, quando inexistente ou fraco o El Niño, o volume de chuvas aumenta na região. 

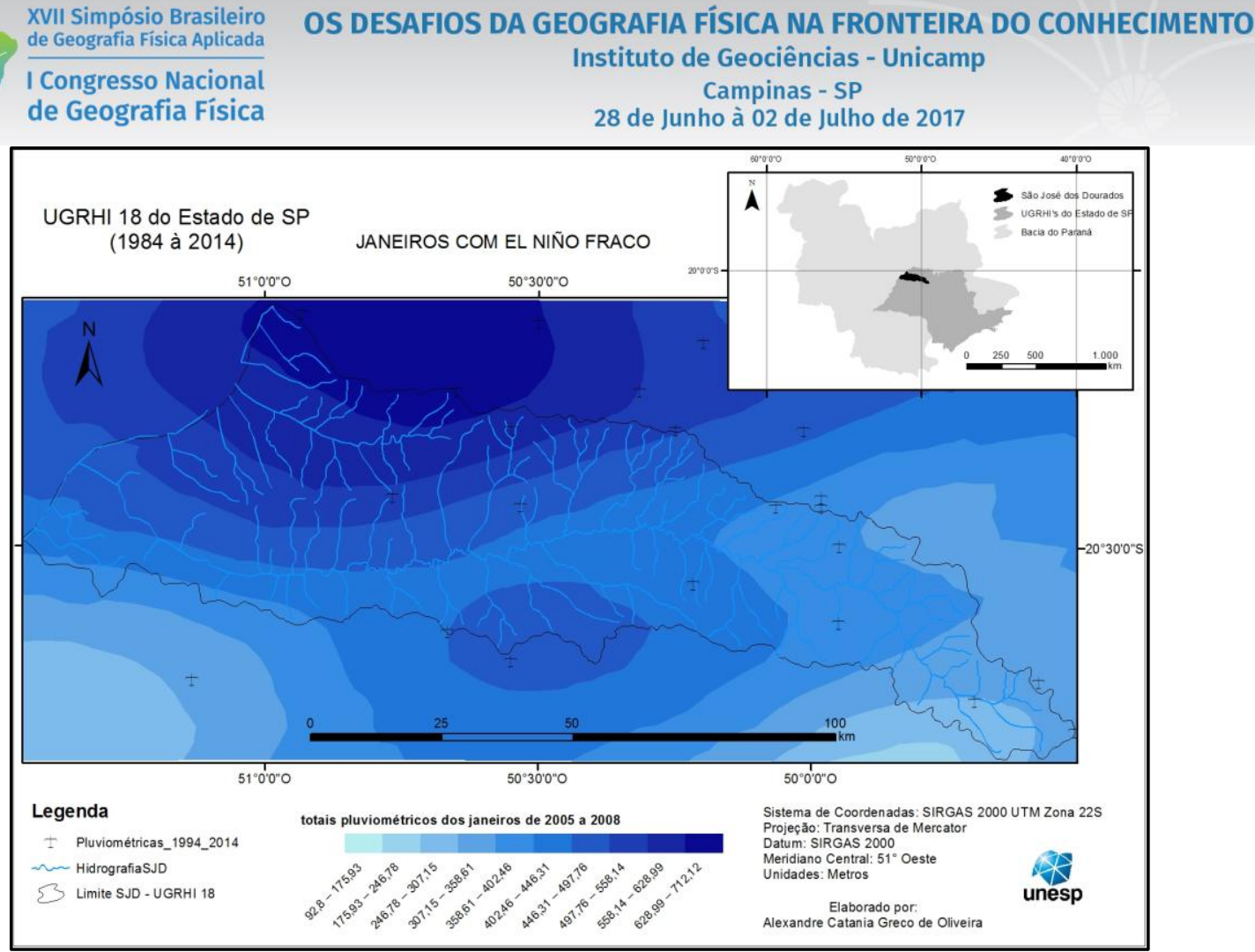

Figura 7: Janeiros entre os anos de 2005 a 2008, período considerado com El Niño fraco.

Observando os dados e aplicando uma média simples as estações para períodos úmidos entre os anos de 1983 a 1987, ou seja, um período de cinco anos de um dos ENOS mais fortes registrados, um super El Niño e observando também com uma média simples as mesmas estações nos verões dos anos de 2004 à 2008, considerados anos com El Niño de fraca intensidade, a diferença pluviométrica é da ordem de aproximadamente 15\%, a média de chuva no período úmido para as estações de 83 a 87 é de $790,88 \mathrm{~mm}$ e a média de chuva no período úmido para os anos de 2004 a 2008 é de 910,32 mm.

O mapa anterior compila a pluviosidade da região, o norte apresenta os maiores índices de pluviosidade para o mês de janeiro, desta forma, pode-se observar significativa variabilidade da precipitação pluvial, através da análise de anomalias para os anos e para o quadrimestre na área de abrangência da bacia hidrográfica São José dos Dourados.

\section{Conclusão:}

O método da regressão linear simples para o preenchimento de falhas do banco de dados de precipitação da BHSJD, fornecido pela ANA, apresentou-se viável possibilitando o estudo da espacialização da chuva nesta bacia hidrográfica. A análise de 31 anos de precipitação pluvial da BHSJD mostrou marcada variabilidade. Essas variabilidades muitas vezes podem estar associadas a ocorrência de eventos ENOS - fase positiva (El Niño). Alguns períodos de El Niño considerado fraco apresentam volume de precipitação acima da média normal. Em outros, quando o El Niño é 
considerado forte, a precipitação foi menor apresentando uma relação inversa entre a intensidade dos ENOS (fase positiva) e o total pluviométrico na área estudada.

\section{Agradecimentos:}

Em especial aos professores Dra. Ana Cláudia Carfan, Dr. Edson Luís Piroli, Dr. Jonas Teixeira Nery e Dr. Matheus Ricardo Nogueira Vilanova pelo incentivo nas horas difíceis, pela paciência ao transmitir os conhecimentos para esse tipo de análise e também a instituição Unesp que proporciona esses encontros para o desenvolvimento dos trabalhos acadêmicos.

\section{Bibliografia:}

AGÊNCIA NACIONAL DE ÁGUAS; Orientações para consistência de dados pluviométricos / Agência Nacional de Águas; Superintendência de Gestão da Rede Hidrometeorológica. -- Brasília: ANA, SGH, 2012.

ALESP, Assembleia Legislativa do Estado de São Paulo, SP, Disponível no site: http://indicesilp.al.sp.gov.br/view/index.php?prodCod=1. Acesso em 24 jan. 2017.

CAVAlCANTI; Iracema F.A. ...[et al.] organizadores; Tempo e Clima no Brasil; São Paulo: Oficina de Textos; 2009.

CEPAGRI, Meteorologia UNICAMP, SP: Disponível no site: http://www.cpa.unicamp.br/outrasinformacoes/clima-dos-municipios-paulistas.html. Acesso em 24jan. 2017.

CBH-SJD, Comitê da Bacia Hidrográfica do Rio São José dos Dourados, SP Disponível no site:http://www.comitesjd.sp.gov.br/cbhsjd/downloads/category/11-ano-2013. Acesso em 24 jan. 2017.

CONSELHO ESTADUAL DE RECURSOS HÍDRICOS, Plano Estadual de Recursos Hídricos 2004/2007, SP Disponível no site: ftp://ftp.sp.gov.br/_ftpcomitepcj/PERH/04-07_UGRHI-18.pdf. Acesso em 24jan. 2017.

YAMAMOTO, J. K.; LANDIM, P. M. B. Geoestatística: conceitos e aplicações. São Paulo: Oficina de Textos, 2013.

MARTINELLI Marcello, "Clima do Estado de São Paulo », Confins [Online], 8 | 2010, posto online no dia 14 Março 2010, consultado o 24 Janeiro 2017. URL : http://confins.revues.org/6348 ; DOI : 10.4000/confins.6348

MENDONÇA, Francisco; Climatologia: noções básicas e climas do Brasil; São Paulo: Oficina de Textos; 2007.

OLIVEIRA, Givan Sampaio de;O El Niño e Você - o fenômeno climático, Editora Transtec - São José dos Campos (SP), março de 2001. Disponível no site: http://enos.cptec.inpe.br/elnino/pt. Acesso em 24jan. 2017.

PORTO, Monica F. A.; PORTO, Rubem La Laina. Gestão de bacias hidrográficas. Estud. av., São Paulo, v.22, n.63, p.43-60,2008. Disponível no site: http://www.scielo.br/scielo.php?script=sci_arttext\&pid=S0103-40142008000200004\&lng=pt\&nrm=iso> acessos em 13 mar. 2017.

VIANELLO; Rubens Leite: Meteorologia básica e aplicações / Rubens Leite Vianello, Adir Rainier Alves - $2^{\mathrm{a}}$ Edição - Rev. Ampl. - Viçosa, MG: Ed. UFV, 2012. 